\title{
Competency Evaluation Model for the Software Development Team
}

\author{
Dandan Liu ${ }^{a *}$, Wei Peng ${ }^{a}$, and Wei Liu ${ }^{b}$ \\ ${ }^{a}$ School of Commerce, Shandong University at Weihai, China \\ ${ }^{b}$ School of economics and management, Harbin Institute of Technology at Weihai, China \\ *Corresponding author: Dandan Liu, Doctorate, lecturer, liudandan62@163.com
}

\begin{abstract}
Competency evaluation of computer software development team members is an important issue. Under a comprehensive summary of the competency research, competency evaluation index system for software development team is built in this paper. On this basis, competency identification and evaluation model for the software development team is proposed. The model uses the weighting method based on individual advantage and the VIKOR method based on Lp-metric aggregation function. It takes into account the decision-making preferences of the decision makers and the individuality advantage of the team numbers so as to reflect the difference between the team members more realistically. Finally, an example is given to prove the effectiveness and practicality of the proposed model.
\end{abstract}

Key Words: software development; competency evaluation; individuality advantage

\section{Introduction}

Computer software development not only is one of the main components of the current information technology industry, but also is an important aspect of the enterprise information. The specific development work of many software companies are carried out by this particular form - team, and team has become the most popular working mode in modern organizations (Colomo-Palacios et al., 2012; Lu et al., 2011). Doherty and King and others (McLeod and MacDonell, 2011) found that organizational problems and technical issues are equally important in software development or even more important than the technical issues. Organization is the factor affects the overall situation of software development project, and technology affect only partial (Yang H.D., Kang H.R. and Mason R.M., 2008; Warkentin et al., 2009). Some scholars have already concerned organizational issues in software development and the research content including software development communication and coordination among team members, trust mechanism build, knowledge sharing, etc (Lin, 2011). Zhao Yang and others established a software development team's trust mechanism based on the knowledge management perspective (Yang and Chen, 2008). Parolia who analyzed the relationship between horizontal and vertical coordination and project performance, found the horizontal and vertical coordination can effectively promote knowledge transfer and clear tasks, and thus enhance team performance (Parolia et al., 2007). Yang and others proposed using shared mental models to improve learning ability and performance of development team. However, the current research lacks of members qualified 
situation in software development team. Therefore, this paper analyzes competency of software development team members and gives the key competency, on this basis, builds the competency evaluation model for the software development team members. The model for evaluating competency evaluation simultaneously identify personality strengths can better reflect the differences among evaluation objects so as to have important practical significance for the organization and management of team members.

\section{Competency Analyses on Software Development Team}

Competency study was a hot issue of organizational behavior and human resource management field during nearly 30 years (Jia et al., 2010). Competency research was first proposed by David C. Mcclelland in an article "Testing Competence rather than Intelligence" published in 1973 (McClelland, 1973). In it competency was defined: knowledge, skills, abilities, traits and motivations directly linked to the important function in work or life. A large number of competency research has focused on management functions competency, such as, Boyatzis proposed the competency model for managers (Boyatzis, 1982), including six competency areas and 19 sub-competency, be extended to almost all sectors, resulting in a significant impact. Richard E. Boy proposed the onion model of job competency, which laid the foundation for exploring all kinds of job competency systematically and comprehensively. Furthermore Spencer and others analyzed and summarized on kinds of job competency presented the iceberg model of competency which covers six areas: motivation, character, self-image, social roles, knowledge and skills (Spencer and Spencer, 1993). During information technology development process, competency of relevant staff also attracted the concern of scholars, such as Keng analyzed on the competency for software development team members, including: attitude or motivation, level of knowledge, communication skills, work or cognitive abilities (Keng et al., 2010). According to the existing literature, comprehensive summary on the job competency and competency of software development team, consolidate results of these preliminary studies, so competency evaluation index system for software development team is grouped into six areas: achievement orientation, level of knowledge, communication skills, thinking skills, service orientation, teamwork.

\section{Methods and Models}

\subsection{The research methods}

According to the competency evaluation content for software development team, competency evaluation for software development team involves a number of evaluation indexes, which integrated sum generally includes weighting method and aggregation models. Weighting method generally includes objective weighting method, subjective weighting method and the combination of objective and subjective weighting method (Liu and Li, 2009; Zhou et al., 2008). Based on the competitive and selection function of competency evaluation, this paper takes weighting method based on individual advantage, which is the objective weighting 
method. On one hand the method can avoid arbitrariness lead by subjective factors involvement. On the other hand it also gives opportunities to the object which reflects their own competitive advantages and results, also the principle of fair competition. The model uses VIKOR method based on Lp-metric aggregation function. Comparing with the commonly used TOPSIS method, this method maximizes the utility and provides a variety of groups summed ways and is easier for decision-makers to accept. (Show in Table 1)

Table 1: The contents of competency evaluation index system for software development team

\begin{tabular}{ll}
\hline \multicolumn{1}{c}{ Competency } & \multicolumn{1}{c}{ Contents } \\
\hline $\begin{array}{l}\text { Achievement } \\
\text { orientation }\end{array}$ & $\begin{array}{l}\text { Tenacity, self-motivated, self-confidence, self-positioning } \\
\text { and evaluation }\end{array}$ \\
\hline $\begin{array}{l}\text { Level of } \\
\text { knowledge }\end{array}$ & $\begin{array}{l}\text { Professional knowledge level, learning ability, develop experience } \\
\text { summary ability, ability to collect and collate relevant } \\
\text { information }\end{array}$ \\
\hline $\begin{array}{l}\text { Communication } \\
\text { skills }\end{array}$ & $\begin{array}{l}\text { The ability to establish and maintain relationships with team } \\
\text { members, empathy, affinity, etc. }\end{array}$ \\
\hline Thinking skills & $\begin{array}{l}\text { Ability to understand tasks, the ability to analyze and solve problems, } \\
\text { proper arrangements activities, proactively identify potential problems, } \\
\text { etc. }\end{array}$ \\
\hline Service orientation & Initiative, integrity, strict self-discipline, task-oriented, etc. \\
\hline Teamwork & $\begin{array}{l}\text { Actively participate in the team discussions, assist other members in } \\
\text { addressing problems, emphasis on team collective interests }\end{array}$ \\
\hline
\end{tabular}

\subsection{The Model}

For L software development team members, $\mathrm{K}$ competency evaluation indexes resulting evaluation conclusions (evaluation value) in matrix:

$$
Y=\left[\mathrm{y}_{i j}\right]_{L \times K}=\left[\begin{array}{llll}
\mathrm{y}_{11} & y_{12} & \cdots & y_{1 K} \\
y_{21} & y_{22} & \cdots & y_{2 K} \\
\vdots & \vdots & \vdots & \vdots \\
y_{L 1} & y_{L 2} & \cdots & y_{L K}
\end{array}\right]
$$

Competency identification and evaluation model for the software development team is as follows:

Step1: Determine competency weight: In the evaluation, the weighting factor is a crucial factor, which in practice has important guiding significance. It represents people's value orientation of comprehensive evaluation. In the process of software development team's composition and construction, appraised and select staff is needed, which all belong to comprehensive evaluations. In the process of weight setting links of evaluation, software developers are given to the ability to compose their own voice and the opportunities to express their own strengths and achievement, and in which to be reflected. These can better tap software developers' relevant information and reflect the principle of fair competition (Jia et al., 2011), then establish the value orientation which can best embody their own competitive advantages to express strengths and achievements. In order to understand the specific object being evaluated $y_{i}$ 's personality strengths, this paper starts from the point of view "maximize their own interests" of evaluation object and personal competency evaluation 
information of software developers to build personalized recognition model in order to get $\mathrm{W}_{\mathrm{i}}$ represents weight vector of software developers. Specific process is as follows:

(1) Determine the positive and negative ideal value. Reference the positive and negative ideal value of VIKOR method, assume $\mathrm{y}_{\mathrm{j}}{ }^{*}$ and $\mathrm{y}_{\mathrm{j}}{ }^{-}$are positive ideal value and negative ideal value, and $1 \leqslant \mathrm{j} \leqslant \mathrm{k}$, when the evaluation index $\mathrm{C}_{\mathrm{j}}$ is maximized, it can be calculated by the formula:

$$
\left\{\begin{array}{l}
\mathrm{y}_{j}{ }^{*}=\operatorname{Max}_{i} y_{i j} \\
y_{j}{ }^{-}=\operatorname{Min}_{i} y_{i j} \\
(i=1,2, \cdots, l)
\end{array}\right.
$$

When the evaluation index $C_{j}$ is minimized, it can be calculated by the formula:

$$
\left\{\begin{array}{l}
y_{j}{ }^{*}=\operatorname{Min}_{i} y_{i j} \\
y_{j}{ }^{-}=\operatorname{Max}_{i} y_{i j} \\
(i=1,2, \cdots, l)
\end{array}\right.
$$

Put all the positive ideal values of evaluation index together, and get an optimal solution, on the contrary, put all the negative ideal value of evaluation index together to obtain a worst solution.

(2) Determine the weight vector $\mathrm{W}_{\mathrm{i}}$ on behalf of the software development team members. Software development team who express their interest demands, affect the final results of the evaluation. Its manifestations is to select weight setting option for its favorable. Since VIKOR is also the sum method based on distance point idea, so when an evaluation index of evaluation object has obvious advantages, the corresponding increasing of the evaluation weight can significantly improve the overall evaluation findings. It is the most advantageous, so based on this idea, for $y_{i}$ the weight vector of its individual identification model is set to:

$$
\left\{\begin{array}{l}
w_{i j}=\frac{1}{\left(y_{\mathrm{j}}^{*}-y_{i j}\right)^{2} * \sum_{j}^{n} \frac{1}{\left(y_{\mathrm{j}}^{*}-y_{i j}\right)^{2}}} \\
\sum_{j}^{n} w_{\mathrm{ij}}=1 \\
(i=1,2, \cdots l)
\end{array}\right.
$$

In the formula (3), $i$ is the specific object being evaluated, $\mathrm{j}$ is the evaluation index, $\mathrm{n}$ is the maximum number of the evaluation index.

Step2: Calculate the final evaluation value: $I_{i}=\left(I_{1}, I_{2}, \ldots, I_{1}\right)$ represent the i software developer, evaluation value under weight vector of $m$ group. $\mathrm{D}_{\mathrm{i}}$ represent average evaluation value when all weights value as $\mathrm{W}_{\mathrm{i}}$, the formula is as follow:

In formula, $I=\left(I_{1}, I_{2}, \ldots, I_{1}\right)$ means final evaluation values of software developer's, $S=\left(S_{1}\right.$, $\left.\mathrm{S}_{2}, \ldots, \mathrm{S}_{\mathrm{l}}\right), \mathrm{R}=\left(\mathrm{R}_{1}, \mathrm{R}_{2}, \ldots, \mathrm{R}_{\mathrm{l}}\right)$ are respectively software developers' competency evaluation value and the relative proximity of corresponding positive and negative ideal value. $\mathrm{v}$ is the decision-making mechanism coefficient, generally takes 0.5 . When $\mathrm{v}$ is greater than 0.5 
means making decisions according to the majority resolution way, when $\mathrm{v}$ is similar to 0.5 means making decisions according to the endorse situation, when $\mathrm{v}$ is less than 0.5 means that decision-making based on the case of refusal. $\mathrm{S}^{*}$ is the maximum utility for the group. $\mathrm{R}^{*}$ is the minimum individual regret.

$$
\left\{\begin{array}{l}
\mathrm{D}_{i}=\frac{1}{m} \sum_{i}^{l} I_{i} \\
I_{i}=v\left[\frac{\sum_{j}^{k} w_{j}\left(y_{j}^{*}-y_{i j}\right) /\left(y_{j}^{*}-y_{j}^{-}\right)-\operatorname{Min} s_{i}}{\operatorname{Max} s_{i}-\operatorname{Mins}_{i}}\right] \\
+(1-v)\left[\frac{\operatorname{Max}\left[w_{j}\left(y_{j}^{*}-y_{i j}\right) /\left(y_{j}^{*}-y_{j}^{-}\right)\right]-\operatorname{Min} R_{i}}{\operatorname{Max} R_{i}-\operatorname{Min} R_{i}}\right] \\
S_{i}=\sum_{j}^{k} w_{i j}\left(y_{j}^{*}-y_{i j}\right) /\left(y_{j}^{*}-y_{j}^{-}\right) \\
R_{i}=\operatorname{Max}_{j}\left[w_{i j}\left(y_{j}{ }^{*}-y_{i j}\right) /\left(y_{j}{ }^{*}-y_{j}^{-}\right)\right] \\
(i=1,2, \cdots l)
\end{array}\right.
$$

Step3: Sort of software development team members: According to small to large sort of the $D_{i}$ value, get priority sequence of software development team members, the top surface of the software development team members is better than the back of the software development team members.

\section{Case Study}

Table 2: Team member evaluation result

\begin{tabular}{|c|c|c|c|c|c|c|}
\hline Indicators $\backslash$ Member & $\begin{array}{c}\text { Member } 1 \\
\quad\left(\mathrm{~T}_{1}\right)\end{array}$ & $\begin{array}{c}\text { Member } 2 \\
\left(\mathrm{~T}_{2}\right)\end{array}$ & $\begin{array}{c}\text { Member } 3 \\
\left(\mathrm{~T}_{3}\right)\end{array}$ & $\begin{array}{c}\text { Member } 4 \\
\left(\mathrm{~T}_{4}\right)\end{array}$ & $\begin{array}{l}\text { Member } 5 \\
\quad\left(\mathrm{~T}_{5}\right)\end{array}$ & $\begin{array}{c}\text { Member } 6 \\
\left(\mathrm{~T}_{6}\right)\end{array}$ \\
\hline $\begin{array}{l}\text { Achievement } \\
\text { orientation }\left(\mathrm{C}_{1}\right)\end{array}$ & 8 & 9 & 6 & 5 & 5 & 8 \\
\hline Knowledge $\left(\mathrm{C}_{2}\right)$ & 6 & 8 & 8 & 9 & 7 & 7 \\
\hline Communication $\left(\mathrm{C}_{3}\right)$ & 5 & 7 & 5 & 8 & 4 & 8 \\
\hline Thinking ability $\left(\mathrm{C}_{4}\right)$ & 9 & 6 & 7 & 6 & 5 & 6 \\
\hline Service orientation $\left(\mathrm{C}_{5}\right)$ & 7 & 9 & 6 & 5 & 5 & 9 \\
\hline Teamwork $\left(\mathrm{C}_{6}\right)$ & 6 & 8 & 6 & 5 & 7 & 9 \\
\hline
\end{tabular}

Software development process includes problem definition, feasibility studies, overall design, detailed design, comprehensive testing, maintenance and a series of steps. Competency for different stages of team members focuses on different requirements, so the dominant feature recognition and evaluation of members of information systems is able to lay a good foundation for rational labor division of development information systems development teams. In order to further illustrate steps of the software development team members competency evaluation model, this paper takes an example of a software development team to conduct empirical analysis. The software team is responsible for the use of the data accumulated by EPR systems to develop decision support systems oriented business units. Team consists of six members, scoring for competency (including achievement orientation $\left(\mathrm{C}_{1}\right)$, knowledge $\left(\mathrm{C}_{2}\right)$, communication $\left(\mathrm{C}_{3}\right)$, thinking ability $\left(\mathrm{C}_{4}\right)$, service orientation $\left(\mathrm{C}_{5}\right)$, teamwork $\left(\mathrm{C}_{6}\right)$, etc. 
of member by a responsible person familiar with every member. Each competency uses 10-point scale and subjects give consent level for each competency, the election of the higher numbers means more favor when scoring. 1 score is the lowest point that means it is disagreed with the competency. 10 score is the highest score that means is agreed with the competency very much. Then obtain the six members of the software development team's scores on six indicators, scoring results are shown in Table 2.

Step1: Determine the positive ideal solution and negative ideal solution: In the six competency indicators, all for maximizing indicators, the bigger the better, that is income-guidelines. According to equation (2), calculate positive ideal solution and negative ideal solution of competency indicators. The results are shown in Table 3.

Table 3: Positive ideal solution and negative ideal solution of competency evaluation indicators

\begin{tabular}{lcccccc}
\hline & $\begin{array}{c}\text { Achievement } \\
\text { orientation } \\
\left(\mathrm{C}_{1}\right)\end{array}$ & $\begin{array}{c}\text { Knowledge } \\
\left(\mathrm{C}_{2}\right)\end{array}$ & $\begin{array}{c}\text { Communicat } \\
\text { ion }\left(\mathrm{C}_{3}\right)\end{array}$ & $\begin{array}{c}\text { Thinking } \\
\text { ability } \\
\left(\mathrm{C}_{4}\right)\end{array}$ & $\begin{array}{c}\text { Service orientati } \\
\text { on }\left(\mathrm{C}_{5}\right)\end{array}$ & $\begin{array}{c}\text { Teamwork } \\
\left(\mathrm{C}_{6}\right)\end{array}$ \\
\hline $\begin{array}{l}\text { Positive ide } \\
\text { al solution }\end{array}$ & 9 & 9 & 8 & 9 & 9 & 9 \\
$\begin{array}{l}\text { Negative } \\
\text { ideal }\end{array}$ & 5 & 6 & 4 & 5 & 5 & 5 \\
\hline
\end{tabular}

Step2: Determine the weight setting program of members' view of the software development

team: According to the value situation of team members evaluation, according to the formula 3, obtain the weight vector of team members' view in Table 4:

Table 4: Weight setting program

\begin{tabular}{lllllll}
\hline & T1 & T2 & T3 & T4 & T5 & T6 \\
\hline$\left(\mathrm{C}_{1}\right)$ & 0.28 & 0.28 & 0.07 & 0.01 & 0.08 & 0.14 \\
$\left(\mathrm{C}_{2}\right)$ & 0.03 & 0.14 & 0.59 & 0.47 & 0.33 & 0.03 \\
$\left(\mathrm{C}_{3}\right)$ & 0.03 & 0.14 & 0.07 & 0.47 & 0.08 & 0.27 \\
$\left(\mathrm{C}_{4}\right)$ & 0.56 & 0.02 & 0.15 & 0.03 & 0.08 & 0.02 \\
$\left(\mathrm{C}_{5}\right)$ & 0.07 & 0.28 & 0.07 & 0.01 & 0.08 & 0.27 \\
$\left(\mathrm{C}_{6}\right)$ & 0.03 & 0.14 & 0.07 & 0.01 & 0.33 & 0.27 \\
\hline
\end{tabular}

From the contents of table 4, take team number T1 for example. In the fourth item (thinking ability) value of its weight setting program (the weight coefficients) is 0.56 , indicating that its maximum personality advantage characteristics reflect the competency indicators. In this indicator, the other five team members have a wide gap with it and have an absolute advantage. It is not difficult to see that the weights set program reveals the personality strengths competency of the software development team members. According to the differences in personality strengths, combined with the staff's personality preferences and assisted step 3 for the final evaluation value, decision-makers can make related decisions.

Step3: Final evaluation value of software development team members: Make decision preference based on agreed conditions, therefore set mechanism coefficient as 0.5 , the final evaluation by the formula 5 is:

$$
P_{1}=\{0.610,278,0.594,0.570,0.900,0.2590 .610,0.278,0.594,0.570,0.900,0.259\}
$$

In order to compare and analyze the result of the method $\left(\mathrm{P}_{1}\right)$, use TOSIS method ( $\mathrm{Li}$ et al., 2011) to comprehensively evaluate software development team members. The evaluation 
process uses weights based on information entropy weight setting program (P2). The introduction of information entropy weight setting program is mainly on account of weight setting programs of this paper and weight setting program based on information entropy are all objective weighting method, facilitate comparison features. Final conclusions are shown in Table 5, the number in parentheses indicates sort.

Content following table shows that the method of this paper and compared method has some differences. In the optimal and suboptimal choice of software development team members, two methods of the paper identified software development team members are team members 6 , team member 2 . The number of 3, 4 and 5 member have large differences, the differences is mainly from the weight setting program, because the P1 method of weight setting program concerns more about personality dominant differences and the P2 method concerns more about information carried by evaluation indicators. From the foregoing analysis, this method takes into account the decision making preference of decision maker and personality strengths of team members and reflect the differences among team members more realistically. Finally, based on the final assessment conclusions sorting, combining the competency advantages of team members, team members 6 in this example is the best team members.

Table 5: Evaluation result

\begin{tabular}{lllllll}
\hline & T1 & T2 & T3 & T4 & T5 & T6 \\
\hline $\mathrm{P}_{1}$ & 0.610 & 0.278 & 0.594 & 0.570 & 0.900 & 0.259 \\
& $(5)$ & $(2)$ & $(4)$ & $(3)$ & $(6)$ & $(1)$ \\
$\mathrm{P}_{2}$ & 0.481 & 0.744 & 0.284 & 0.445 & 0.143 & 0.775 \\
& $(3)$ & $(2)$ & $(5)$ & $(4)$ & $(6)$ & $(1)$ \\
\hline
\end{tabular}

\section{Conclusion}

Against the competency evaluation of software development team member, this paper overall summarizes the competency related research results, builds evaluation index system for software development team competency, which for the software development team members scientific and standardized selection, configuration, laid the foundation. On the basis, it conducts the competency identification and evaluation model for the software development team. On the one hand, the model strengthens the depth mining of original indicator data by introducing the advantages identification ideological, achieves the individual advantages identification of team members, whereby the formation of weight setting program. Compare with the commonly used AHP method and entropy weight method and other empowerment methods, it respects for the views of each evaluators to form conclusion more readily accept by evaluators, avoiding drawbacks of evaluation ranked as the final result failed to reveal the inherent law of competency evaluation and improve the usability of evaluation model. On the other hand, VIKOR method provides three new indicators sum method for decision makers to choose, and it is better than the single mode sum of the TOPSIS, PROMETHEE methods which did not consider the lack of policy makers' diversity in decision-making mode. Finally, take software development team evaluation for a software enterprise as an example and apply on the proposed evaluation model. The results show that the evaluation model is workable 
and practical. It can provide effective reference for the user to reasonable form and software development team.

\section{Acknowledgements}

Thanks for the financial support from the fund of social science planned project from Shandong province of China.

\section{References}

1. R.E. Boyatzis, The competent management: a model for effective performance. New York: John Wliey(1982).

2. R. Colomo-Palacios, C. Casado-Lumbreras, P. Soto, S. Misra and F.J. Garcia, Analyzing Human Resource Management Practices Within the GSD Context. Journal of Global Information Technology Management, 15(2012): 30-54.

3. J.F. Jia, X.N. Zhao and S.M. Sun, An evolution method of organizational performance based on the comparative advantage and empirical Research. Journal of Science Research Management, 32(2011): 151-159.

4. J.F. Jia, X.N. Zhao and X. Wen, The Retrospect and Prospect of Managerial Competency. Journal of Forecasting, 29(2010): 74-80.

5. S. Keng, T.Xin And S. Hong, Important characteristics of software development team members: an empirical investigation using 20(2010): 563-580.

6. G. Li, G.T. Chi and Y.Q. Cheng, Evaluation model and empirical study of human all-round development based on entropy weight and TOPSIS. Journal of Systems Engineering, 26(2011): 400-407.

7. C.P. Lin, Modeling job effectiveness and its antecedents from a social capital perspective: A survey of virtual teams within business organizations. Journal of Computers in Human Behavior, 27(2011): 915-923.

8. Y.P. Liu and Y.J. Li, Decision model for partner selection based on preference information of decision-makers. Journal of Systems Engineering and Electronics, 31(2009): 602-605.

9. Y.B.Lu, C.J. Xiang, B. Wang and X.P. Wang, what affects information systems development team performance? An exploratory study from the perspective of combined socio-technical theory and coordination theory. Journal of Computers in Human Behavior, 27(2011): 811-822.

10. D.C.McClelland, Testing for competence rather than for intelligence. Journal of American Psychologist, 28(1973): 1-14.

11. L.McLeod and S.G. MacDonell, Factors that Affect Software Systems Development Project Outcomes: A Survey of Research. Journal of ACM Computing Surveys, 43(2011): 24-56. 
12. N.Parolia, S. Goodman, Y. Li, et.al., Mediators between coordination and IS Project Performance. Journal of Information \& Management, 44(2007): 635-645.

13. L.M. Spencer and S.M. Spencer, Competence at Work: Models for Superior Performance. John Willey \& Sons, Inc. 1993.

14. M.Warkentin, R.S. Moore, E. Bekkering and A.C. Johnston, Analysis of Systems Development Project Risks: An Integrative Framework. Journal of Data Base for Advances in Information Systems, 40(2009): 8-27.

15. H.D.Yang, H.R. Kang and R.M. Mason, An exploratory study on meta skills in software development teams: antecedent cooperation skills and personality for shared mental models. European Journal of Information Systems, 17(2008): 47-61.

16. Z.Yang and S.J. Chen, Trust Mechanism Research of Software Development Team in Knowledge Management Perspective. Journal of Beijing Institute of Technology (Social Sciences Edition), 10(2008): 62-66.

17. R.X. Zhou, S.C. Liu and W.H. Qiu, Survey of applications of entropy in decision analysis. Journal of Control and Decision, 23(2008): 361-371. 